Research Paper

\title{
Isoflavone Genistein Induces Fluid Secretion and Mor- phological Changes in the Uteri of Post-Pubertal Rats
}

\author{
Naguib Salleh ${ }^{1,}$, Mohd Mokhtar Helmy ${ }^{1}$, Kasim Nor Fadila ${ }^{1}$, Soh Onn Yeong ${ }^{2}$ \\ 1. Department of Physiology, Faculty of Medicine, University of Malaya, Lembah Pantai, 50603, Kuala Lumpur Malaysia; \\ 2. Department of Anatomy, Faculty of Medicine, University of Malaya, Lembah Pantai, 50603, Kuala Lumpur Malaysia.
}

$\triangle$ Corresponding author: Tel: 0060379677532 Fax: 0060379674775 E-mail: naguib.salleh@yahoo.com.my.

(ㅇ Ivyspring International Publisher. This is an open-access article distributed under the terms of the Creative Commons License (http://creativecommons.org/ licenses/by-nc-nd/3.0/). Reproduction is permitted for personal, noncommercial use, provided that the article is in whole, unmodified, and properly cited.

Received: 2012.09.II; Accepted: 2013.03.04; Published: 2013.04 .02

\begin{abstract}
A reported increase in the incidence of infertility following high genistein intake could be related to alteration in the normal fluid volume and morphology of the uterus in adult female. In view of this, we investigated the effect of this compound on fluid secretion, fluid volume and morphology of the uterus in post-pubertal rats. Methods: Ovariectomised SD rats were treated with 17- $\beta$ oestradiol (E) $\left(0.8 \times 10^{-4} \mathrm{mg} / \mathrm{kg} / \mathrm{day}\right)$ and genistein $(0.5,5,10,25,50$ and $100 \mathrm{mg} / \mathrm{kg} /$ day $)$ for three days. Following drug-treatment, in-vivo uterine perfusion was performed and the rate of fluid secretion and the volume of fluid in the uterus were determined via changes in weight $(\mu \mathrm{l} / \mathrm{min})$ and F-dextran concentration of the perfusate respectively. The animals were then sacrificed and the uteri were removed for weight determination, morphological analyses and proliferative cell nuclear antigen (PCNA) expression analyses by Western blotting. Results: Subcutaneous genistein treatment resulted in a dose-dependent increase in fluid secretion rate, fluid volume and uterine wet weight. Treatment with $100 \mathrm{mg} / \mathrm{kg} /$ day genistein resulted in a remarkable increase in the rate of uterine fluid secretion, the volume of the uterine luminal fluid as well as the circumference of the uterine and uterine glandular lumen suggesting an excessive fluid accumulation. Meanwhile, there were evidence of glandular hyperplasia and an increase in the expression of PCNA following treatment with 50 and $100 \mathrm{mg} / \mathrm{kg} / \mathrm{day}$ genistein. Conclusion: High genistein intake could potentially cause adverse effects on the uterus by inducing excessive fluid secretion and accumulation as well as hyperplasia.
\end{abstract}

Key words: genistein, uterine fluid, endometrial hyperplasia.

\section{Introduction}

Isoflavone genistein, present in high amount in soy-derived food products [1], possesses weak estrogenic activity due to its partial binding to the oestrogen receptor- $\beta$ (ER- $\beta$ ) [2]. The importance of genistein in female reproduction has drawn lots of attention lately due to the reported adverse effects. Nowadays, genistein can be found as a dietary supplement consumed by women mainly in the developed world. Soy-derived isoflavone supplements which contain high amount of genistein include a concentrated extract of soy isoflavones (Novasoy ${ }^{\circledR 200}$ ) [3] and a low fat protein product such as PRO-FAM 932 soy protein isolate (SPI) [4]. High genistein consumption has been proposed to adversely affect the reproductive functions in female based on the reported high incidence of infertility in sheeps fed with a specific species of clover, 'Trifolium subterraneum', known to contain high amount of isoflavone content [5]. Meanwhile, genistein-related infertility has also been reported in the captive cheetah fed with $50 \mathrm{mg} / \mathrm{kg} /$ day soy-based diet containing high amount of genistein [6]. In humans, however, no adverse effects on the reproduc- 
tive functions have been documented despite of high isoflavone consumption among the Japanese women, at an average of $0.232 \mu \mathrm{mol} / \mathrm{L} /$ day [7].

From the literature review, most reports describing the adverse effects of genistein on female reproduction were obtained from the studies in pre-pubertal animals [8-15]. Treatments with 0.5, 5 and $50 \mathrm{mg} / \mathrm{kg} /$ day genistein in neonatal mice have resulted in a dose-related abnormal and prolonged oestrous cycle in their post-pubertal period [13]. In addition, their fertility rate was also found to be reduced [16]. Meanwhile, treatment with 100 $\mathrm{mg} / \mathrm{kg} /$ day genistein in neonatal mice was also found to cause the development of histopathological features in the uterus later in adult life [16]. Genistein-induced infertility was reported to be due to uterine abnormality rather than poor embryo quality or abnormal plasma sex-steroid levels [13]. In view of this, the mechanisms underlying genistein effect on the uterus that leads to infertility warrant detail investigations.

There is a possibility that this compound could affect the volume and composition of the uterine fluid which will ultimately result in an unfavourable uterine environment for many reproductive processes to occur. In addition, genistein was also reported to affect the morphology of the uterus which could also interfere with the reproductive processes [17]. Changes in uterine morphology could delay or inhibit the transformation of the endometrium into a receptive state, resulting in failure of embryo to implant [18]. Currently, only few studies have reported on the changes in the uterine morphology which include alteration in the thickness of the endometrium and epithelial heights following high doses of genistein treatment [19]. We hypothesized that high genistein intake could induce uterine fluid secretion as well as cause changes to the morphology of the uterus which will ultimately interfere with the reproductive processes. In addition, these changes could also lead to other pathological consequences on the uterus. The aim of this study is therefore to investigate the effect of various doses of genistein on uterine fluid secretion and morphology in adult female uterus in order to explain some of the reported adverse effects related to this compound.

\section{Materials \& Methods}

\section{I Animals preparation}

Three month-old adult female Sprague-Dawley (SD) rats, weighted $\pm 225 \mathrm{~g}$ were housed in a clean and well ventilated animal room with a standardized conditions (lights on $12 \mathrm{hr}$ from 06:00 hours to 18:00 hours: room temperature $24^{\circ} \mathrm{C}$; with $5-6$ animals per cage), with free access to soy-free diet (Food Technology Division, Malaysia Agricultural Research Institute, MARDI) and water free from dissolving endocrine-disrupting chemicals (EDCs) (Chemistry Department, UM) since the time of weaning. All procedures were approved by the Faculty of Medicine, Animal Care and Use Committee (ACUC), UM with ethics number: FIS/01/12/2008 (NFK). Genistein (G-6055) was purchased from LC Laboratories (Woburn, MA, USA) with more than $99 \%$ purity which appear as crystalline powder with light yellow color. E, P, peanut oil and Flourescence-Dextran (F-Dextran) marker $(\mathrm{MW}=450 \mathrm{kDa})$ were purchased from Sigma-Aldrich, UK.

Bilateral ovariectomy was performed under isoflurane anesthesia. After surgery, the animals were given intramuscular injection of $0.1 \mathrm{ml}$ of Kombitrim antibiotic to prevent post surgical wound infection. The animals were then divided into nine groups $(n=6$ per group). The first six groups received subcutaneous genistein treatment at the following doses: $0.5,5$, $10,25,50$ and $100 \mathrm{mg} / \mathrm{kg} /$ day / body weight, for three (3) consecutive days. In addition, another three groups were treated with $0.8 \times 10^{-4} \mathrm{mg} / \mathrm{kg} /$ day E, 1.6 $\mathrm{mg} / \mathrm{kg} /$ day progesterone $(\mathrm{P})$ and peanut oil (vehicle) also for three days. E treated group acts as a positive control known to induce proliferative changes in the uterus [20]. Meanwhile, E and P treated groups were used as positive controls known to induce uterine fluid secretion and absorption respectively [21]. All drug treatment were started at least ten days after ovariectomy to eliminate the effect of endogenous sex-steroid as previously described [22]. The drugs were dissolved in peanut oil and were administered via a subcutaneous injection behind the neck cuff. In order to ensure maximum solubility, genistein was first dissolved in $0.1 \mathrm{ml}$ DMSO which was then diluted in series to achieve the desired final concentrations prior to mixing with the peanut oil. Meanwhile, $0.1 \mathrm{ml}$ DMSO alone was mixed with peanut oil and injected into the ovariectomised rats to observe its effects on the measured uterine parameters.

\subsection{Determination of Uterine Wet Weight}

Uterine horns were immediately excised after the animals were sacrificed and a gentle external pressure was applied on the uterus to squeeze out the uterine fluid. The surrounding fat was trimmed and the tissue was immediately weighed using electronic balance (EL3002 METTLER TOLEDO).

\subsection{In-vivo Uterine Perfusion}

The animals were anaesthetized by intraperitoneal injection of pentobarbital nembutal at $0.06 \mathrm{ml} / 100 \mathrm{~g}$ body weight prior to the experiment. 
The animals were confirmed to be fully anaesthetised when no reaction was noted upon gentle pinching of the foot which was then placed on a heat pad throughout the experiment to maintain a constant body temperature at $37^{\circ} \mathrm{C}$. Two parallel incisions were made at both flanks to expose the distal end of the uterine horns. An inflow fine-bore polythene tube of $15 \mathrm{~cm}$ long (ID $0.38 \mathrm{~mm}$ : OD $1.09 \mathrm{~mm}$ ) was inserted into the uterine lumen and was tied in-situ at the uterotubal junction. A ventral incision was made to insert a $10 \mathrm{~cm}$ outflow tube with similar diameter through a cervical incision and was tied in-situ at the uterocervical junction. The inflow and outflow tubes and the animal were at the same height to minimize the gravitational effect. A Standard Infuse Harvard Pump 11 Advance by HARVARD APPARATUS, USA was used to deliver the perfusate at a constant rate of $1.3 \mu \mathrm{l} / \mathrm{min}$ [21]. The inflow tube was initially filled with the perfusate prior to starting the perfusion. The perfusion fluid contained the following: 110.0 $\mathrm{mmol} / \mathrm{L} \mathrm{NaCl}, 14.3 \mathrm{mmol} / \mathrm{L} \mathrm{Na}_{2} \mathrm{HCO}_{3}, 1.0 \mathrm{mmol} / \mathrm{L}$ $\mathrm{Na}_{2} \mathrm{HPO}_{4}, 15 \mathrm{mmol} / \mathrm{L} \mathrm{KCl}, 0.8 \mathrm{mmol} / \mathrm{L} \mathrm{MgSO}_{4}, 10.0$ $\mathrm{mmol} / \mathrm{L}$ HEPES, $1.8 \mathrm{mmol} / \mathrm{L} \mathrm{CaCl}_{2}$ and $5.5 \mathrm{mmol} / \mathrm{L}$ glucose and at $\mathrm{pH}$ of 7.34 which were selected to closely mimic the normal composition and $\mathrm{pH}$ of the uterine fluid [21]. $1.0 \mu \mathrm{mol} / 1 \mathrm{~F}-$ Dextran marker (mol. wt. $450 \mathrm{kDa}$ ) was dissolved into the perfusion fluid which acts as a non-absorbable marker to detect any changes in fluid volume. Perfusion was started and maintained at a rate of $1.3 \mu \mathrm{l} / \mathrm{min}$. Once perfusate appeared at the end of the outflow tube, the collection time was started. Fluid collection was made over a period of 3 hours. The collecting tubes were partially submerged into cold water and the tops were covered to minimize evaporation.

The tubes were weighed using an electronic balance (EL3002 METTLER TOLEDO) prior to and after perfusate collection. The rate of uterine fluid secretion was measured by determining the difference between the weight of the tubes prior to and after perfusate collection over a period of 3 hours. F-dextran concentration was determined as follows: samples were diluted 1:250 in PBS and mixed well in a miniature cuvette which was then placed in a Hitachi (F-2000) spectrophotometer which was set at a wavelength of $E_{x}=488 \mathrm{~nm}, E_{M}=520 \mathrm{~nm}$. The procedure was repeated twice for each samples. Spectrophotometer calibration was carried out by serial dilution of the perfusate. Changes in F-dextran concentration (before and after perfusion) reflect either an increase or a decrease in fluid volume which suggest that either secretion or absorption takes place in the uterus.

\subsection{Uterine Morphological Analyses}

A day after the last day of drug treatment, the rats were humanely sacrificed and the uterine horns were immediately removed and fixed in $4 \%$ paraformaldehyde (PFD) at $4^{\circ} \mathrm{C}$ for 4 to 5 hours. The tissues were then processed through different grades of ethanol, incubated overnight in chloroform, transferred into paraffin wax for 3 hours, placed into the molds prefilled with melted wax and cooled immediately at $-60 \circ \mathrm{C}$ to harden the wax. Tissues were then cut into $5 \mu \mathrm{m}$ sections and mounted onto glass slides. The slides were then stained with hematoxylin and eosin (H\&E), visualized under a light microscope under magnifications of 4,20 and 40 times. The circumferences $(\mathrm{C})$ of the uterine lumen and uterine glandular lumen, the heights $(\mathrm{H})$ of the luminal and glandular epithelia as well as the thickness of the endometrium and myometrium were measured using NIS-Elements AR program. Epithelial height was measured from the basolateral to the apical membrane, while myometrial thickness was measured from the beginning of the circular layer to the distal margin of the longitudinal layer. Endometrial thickness was measured from the apical membrane of the luminal epithelia to the beginning of the circular layer of the myometrium. Meanwhile, the mean circumference from six of the largest glands was obtained from each of the uterine section. All images were captured using Nikon Eclipse 80i that was attached to the light microscope (Olympus, Japan).

\subsection{PCNA expression analysis by Western blotting}

Equal amount of protein were loaded for SDS-PAGE electrophoresis, which were blotted onto PVDF membranes (Bio Rad, USA). The blots were then blocked with 5\% BSA at room temperature for 90 minutes. This was then followed by incubation in a primary mouse monoclonal antibody against PCNA (Santa Cruz, USA- catalogue number: sc-25280) at room temperature for 90 minutes at dilution of 1:1000 $(200 \mu \mathrm{g} / \mathrm{ml})$. After washing with PBS-Tween, the blots were exposed to horseradish peroxidase conjugated secondary antibody (Santa Cruz, USA) at room temperature for 60 minutes, at a dilution of 1:2000. The bands produced were developed by using Optic $4 \mathrm{C}$ (Bio Rad, USA). $\beta$-actin (abcam, UK) was used as a loading control. The photos of the blots were captured and the density of each band was determined by using Image J software. Ratio of each band/ $\beta$ actin was considered as the expression level of the target protein. Non immune normal rabbit serum was used as a negative control. No bands were observed in this experiment.

\subsection{Serum Genistein Measurement}

12-hours after the last genistein injection, blood 
was withdrawn from the tail vein and was then placed into a gel separator tube. A duplicate of $50-\mu 1$ samples from each animal were analysed for serum genistein concentration. Samples were mixed with equal volumes of acetonitrile, sonicated for $10 \mathrm{~min}$, and centrifuged $(15,000 \mathrm{rpm}$ for $10 \mathrm{~min})$. Serum samples were loaded onto a C-18 SPE column (J \& W Scientific, Folsom, CA, USA) and washed with $30 \mathrm{ml}$ of distilled water. The washed column was eluted with $1.5 \mathrm{ml}$ methanol, evaporated under vacuum with centrifugation, and re-suspended in methanol for HPLC analysis. Prepared samples were separated by HPLC with a Nova Pak C-18 column $(3.9 \times 150 \mathrm{~mm}$ column, $4-\mu \mathrm{m}$ particles) by using a gradient solvent system consisting of sodium acetate buffer $(50 \mathrm{mM}$, $\mathrm{pH} 4.8)$ and methanol (4:1) mixture and sodium acetate buffer, methanol, and acetonitrile (2:2:1) mixture. The flow rate was $0.5 \mathrm{ml} / \mathrm{min}$ at a temperature of $30^{\circ} \mathrm{C}$. For isoflavone detection, a Waters Photodiode Array (PDA) detector was used, with detection ranging from 210 to $400 \mathrm{~nm}$. The assay had a minimum detection limit of $0.1 \mu \mathrm{mol} /$ liter.

\subsection{Statistical analysis}

Data were reported as mean \pm SEM. One-way analysis of variance (ANOVA) with Tukey's post-hoc comparison was used to compare between treatment groups, where a level of $\mathrm{p}<0.05$ was considered to be statistically significant.

\section{Results}

\section{I Effect of Genistein on Uterine Weight}

In figure 1, a dose-dependent increase in uterine/body weight was noted with increasing doses of genistein treatment. Genistein doses exceeding 10 $\mathrm{mg} / \mathrm{kg} /$ day resulted in a significant increase in uterine/body weight $(\mathrm{p}<0.05)$ as compared to control. Treatment with $100 \mathrm{mg} / \mathrm{kg} /$ day genistein resulted in 10 folds increase while $\mathrm{E}$ treatment resulted in a 14-folds increase as compared to the control group. Meanwhile, treatments with $\mathrm{P}$ and DMSO did not cause any significant changes in this parameter as compared to the control.

\subsection{Effect of Genistein on Uterine Fluid Secre- tion}

In figure 2, a dose-dependent increase in the rate of uterine fluid secretion was observed with increasing doses of subcutaneous genistein treatment. The rate of fluid secretion significantly increased following treatment with genistein at doses exceeding $5 \mathrm{mg} / \mathrm{kg} /$ day genistein as compared to control. Treatment with $50 \mathrm{mg} / \mathrm{kg} /$ day genistein resulted in 1.5 times increased, while $100 \mathrm{mg} / \mathrm{kg} /$ day genistein treatment resulted in 1.9 times increase in the rate as compared to control. Treatment with $\mathrm{P}$ caused a reduction in the rate of uterine fluid secretion $(0.67 \mu \mathrm{l} / \mathrm{min})$ which was 1.42 times lesser than the control, while DMSO treatment did not cause any significant changes in the rate as compared to control.

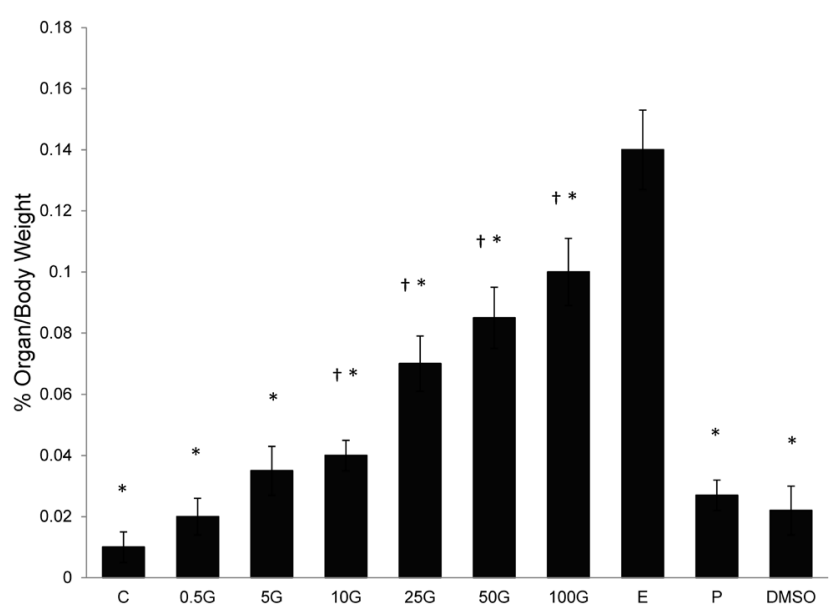

Figure I: The effect of $17 \beta$-oestradiol $(E)$, progesterone $(P)$, peanut oil, DMSO and different doses of genistein : 0.5G (0.5 $\mathrm{mg} / \mathrm{kg} / \mathrm{day}), 5 \mathrm{G}$ (5 mg/kg/day), IOG(I0 mg/kg/day), 25G (25 $\mathrm{mg} / \mathrm{kg} /$ day), $50 \mathrm{G}(50 \mathrm{mg} / \mathrm{kg} / \mathrm{day})$ and $100 \mathrm{G}$ (100 mg/ $/ \mathrm{kg} / \mathrm{day})$ on the percentage increase of uterine over body weight. A dose-dependent increasein this parameter was noted with increasing doses of genistein treatment. Data was expressed as mean \pm SEM, $n=6$. $\dagger(p<0.05$ as compared to the control), $*(p<$ $0.05)$ as compared to $E$.

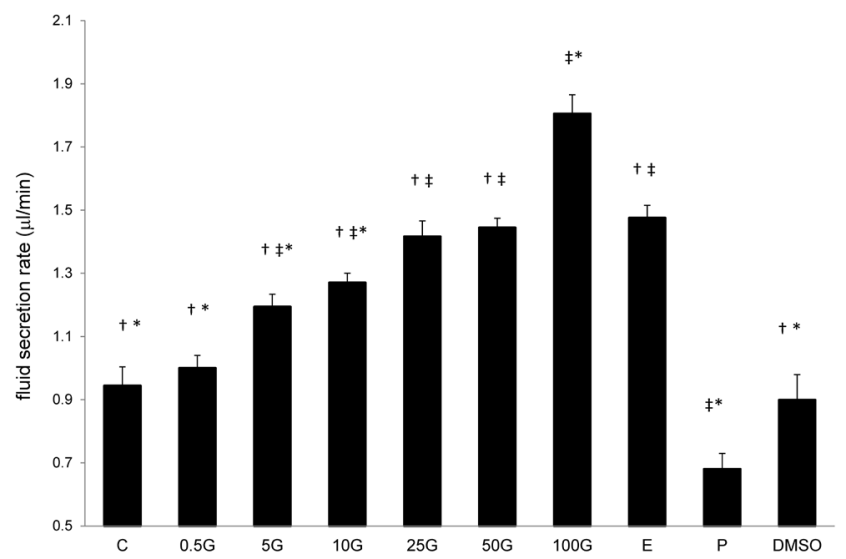

Figure 2: The effect of $17 \beta$-oestradiol $(E)$, progesterone $(P)$, peanut oil, DMSO and different doses of genistein : 0.5G (0.5 $\mathrm{mg} / \mathrm{kg} /$ day $), 5 \mathrm{G}$ (5 mg/kg/day), I0G(I0 mg/kg/day), 25G (25 $\mathrm{mg} / \mathrm{kg} /$ day $), 50 \mathrm{G}(50 \mathrm{mg} / \mathrm{kg} / \mathrm{day})$ and I00G (100 mg/kg/day) on the rate of uterine fluid secretion ( $\mu \mathrm{l} / \mathrm{min})$. A dose-dependent increase in fluid secretion rate was observed with increasing genistein doses. Treatment with $100 \mathrm{G}$ resulted in a significant increase in the rate as compared to $C$ and $E$. E acts as a positive control for fluid secretion, while $P$ acts as a positive control for fluid absorption in the uterus. Data was expressed as mean $\pm S E M, n=6$. $\ddagger$ $(p<0.05)$ as compared to control, $*(p<0.05$ as compared to $E), \dagger$ $(p<0.05$ as compared to $P)$. 
In figure 3, a dose-dependent decrease in F-Dextran concentration was observed with increasing doses of subcutaneous genistein treatment. F-dextran concentration was significantly lower than the control following treatment with genistein at doses exceeding $5 \mathrm{mg} / \mathrm{kg} /$ day. $50 \mathrm{mg} / \mathrm{kg} /$ day genistein treatment resulted in $10 \%$ reduction in F-dextran concentration while the highest reduction $(-15 \%)$ was noted following treatment with 100 $\mathrm{mg} / \mathrm{kg} /$ day genistein. E treatment resulted in $12 \%$ reduction in F-dextran concentration. $\mathrm{P}$ treatment however caused an increase in F-dextran concentration $(+26 \%)$ while treatment with DMSO did not result in any significant changes in F-dextran concentration as compared to control.

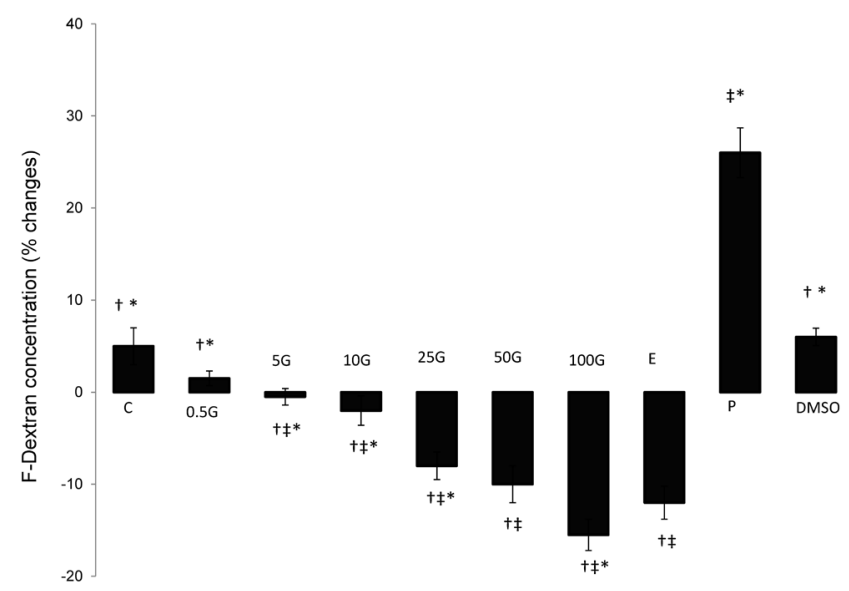

Figure 3 The effect of $17 \beta$-oestradiol $(E)$, progesterone $(P)$, peanut oil, DMSO and different doses of genistein : 0.5G (0.5 $\mathrm{mg} / \mathrm{kg} /$ day $), 5 \mathrm{G}$ (5 mg/kg/day), I0G(10 mg/kg/day), 25G (25 $\mathrm{mg} / \mathrm{kg} /$ day $), 50 \mathrm{G}(50 \mathrm{mg} / \mathrm{kg} /$ day $)$ and I00G (100 mg/kg/day) on the uterine fluid volume as monitored by the percentage changes in F-dextran concentration. Genistein treatment resulted in a dose-dependent reduction in F-dextran concentration, which indicates an increase in the fluid volume. Treatment with I00G resulted in a significant decrease in F-dextran concentration as compared to $\mathrm{E}$. Under $\mathrm{P}$ effect, an increase in F-dextran concentration was noted. Data was expressed as mean $\pm S E M, n=6$. $\ddagger$ $(p<0.05)$ as compared to control, $*(p<0.05)$ as compared to $E, \dagger$ ( $\mathrm{P}<0.05$ as compared to $\mathrm{P})$.

\subsection{Changes in Uterine Morphology}

In figure 4 and table 1 , an increase in the uterine luminal circumference was noted with increasing doses of genistein treatment. At doses exceeding 10 $\mathrm{mg} / \mathrm{kg} /$ day, the increase in the circumference was higher than the control $(\mathrm{p}<0.05)$. Treatment with 50 $\mathrm{mg} / \mathrm{kg} /$ day and $100 \mathrm{mg} / \mathrm{kg} /$ day genistein resulted in 4.65 and 5.82 times increase in the luminal circumferences respectively as compared to control. E treatment resulted in 4.18 times increase while $\mathrm{P}$ treatment did not cause any significant changes in this parameter as compared to control. Treatment with 100 $\mathrm{mg} / \mathrm{kg} /$ day genistein resulted in 1.39 times in the circumference as compared to E-treated group. Meanwhile, DMSO treatment did not cause any significant changes in the circumference as compared to control. It was also noted that the thickness of the myometrium increased with increasing doses of genistein treatment. Genistein at 50 and 100 $\mathrm{mg} / \mathrm{kg} /$ day caused a 1.75 and 2.07 times increase in the myometrial thickness as compared to control. E treatment resulted in 1.40 times increase-while $\mathrm{P}$ treatment did not cause any significant changes in this parameter as compared to control. The thickness of the endometrium increased following treatment with low genistein doses $(0.5,5$ and $10 \mathrm{mg} / \mathrm{kg} /$ day) in a dose-dependent manner, however the thickness was reduced following treatment with higher doses of genistein at 25, 50 and $100 \mathrm{mg} / \mathrm{kg} /$ day. $\mathrm{P}$ treatment did not result in any significant changes in the endometrial thickness as compared to control.

Table I: Analyses of the uterine luminal circumference (C), myometrial and endometrial thicknesses following treatment with different doses of genistein : 0.5G $(0.5 \mathrm{mg} / \mathrm{kg} /$ day $), 5 G \quad(5$ $\mathrm{mg} / \mathrm{kg} /$ day), $10 \mathrm{G}(10 \mathrm{mg} / \mathrm{kg} /$ day $), 25 \mathrm{G}$ ( $25 \mathrm{mg} / \mathrm{kg} /$ day $), 50 \mathrm{G}$ (50 $\mathrm{mg} / \mathrm{kg} /$ day $)$ and $100 \mathrm{G}(100 \mathrm{mg} / \mathrm{kg} /$ day $)$, 17 $\beta$-oestradiol $(\mathrm{E})$, progesterone $(\mathrm{P})$ and DMSO. A dose-dependent increase in the circumference was noted with increasing doses of genistein treatment. I00G treatment resulted in a remarkable increase in the circumference of the uterine lumen. Meanwhile, myometrial thickness increases with increasing doses of genistein. Endometrial thickness however decreases following 50G and I00G treatment as compared to lower genistein doses. Values represent mean \pm SEM with $n=6$ per group. $\dagger(p<0.05$ as compared to control), * $(p<0.05$ as compared to $E)$.

\begin{tabular}{llll}
\hline & $\begin{array}{c}\text { Uterine luminal } \\
\text { Circumference }(\mathbf{C}) \\
(\mu \mathrm{m})\end{array}$ & $\begin{array}{l}\text { Myometrial } \\
\text { Thickness }(\boldsymbol{\mu m})\end{array}$ & $\begin{array}{l}\text { Endometrial } \\
\text { Thickness }(\boldsymbol{\mu m})\end{array}$ \\
\hline Control & $1763.50 \pm 80.58^{*}$ & $98.63 \pm 5.68^{*}$ & $219.77 \pm 10.12^{*}$ \\
0.5G & $1504.61 \pm 68.89^{*}$ & $67.74 \pm 7.43^{*}$ & $269.82 \pm 12.84^{*}$ \\
5.0G & $1681.02 \pm 91.51^{*}$ & $93.14 \pm 6.99^{*}$ & $375.93 \pm 20.49^{\dagger}$ \\
10G & $2697.83 \pm 102.32^{*}$ & $110.65 \pm 5.41^{\dagger *} *$ & $382.12 \pm 18.75^{\dagger}$ \\
25G & $2820.28 \pm 87.66^{*},^{\dagger}$ & $173.42 \pm 8.75^{\dagger}$ & $331.08 \pm 15.21^{\dagger}$ \\
50G & $8215.57 \pm 125.45^{\dagger}$ & $181.04 \pm 10.25^{\dagger *}$ & $344.74 \pm 19.06^{\dagger}$ \\
100G & $10280.74 \pm 100.22^{*},{ }^{\dagger} 204.59 \pm 9.43^{\dagger *}$ & $340.54 \pm 14.21^{\dagger}$ \\
E & $7380.28 \pm 89.65^{\dagger}$ & $148.30 \pm 7.11^{\dagger}$ & $367.35 \pm 10.54^{\dagger}$ \\
P & $1617.33 \pm 72.25^{*}$ & $107.61 \pm 5.69^{*}$ & $256.16 \pm 9.16^{*}$ \\
DMSO & $1744.87 \pm 85.28^{*}$ & $88.94 \pm 8.92^{*}$ & $211.48 \pm 13.09^{*}$ \\
\hline
\end{tabular}



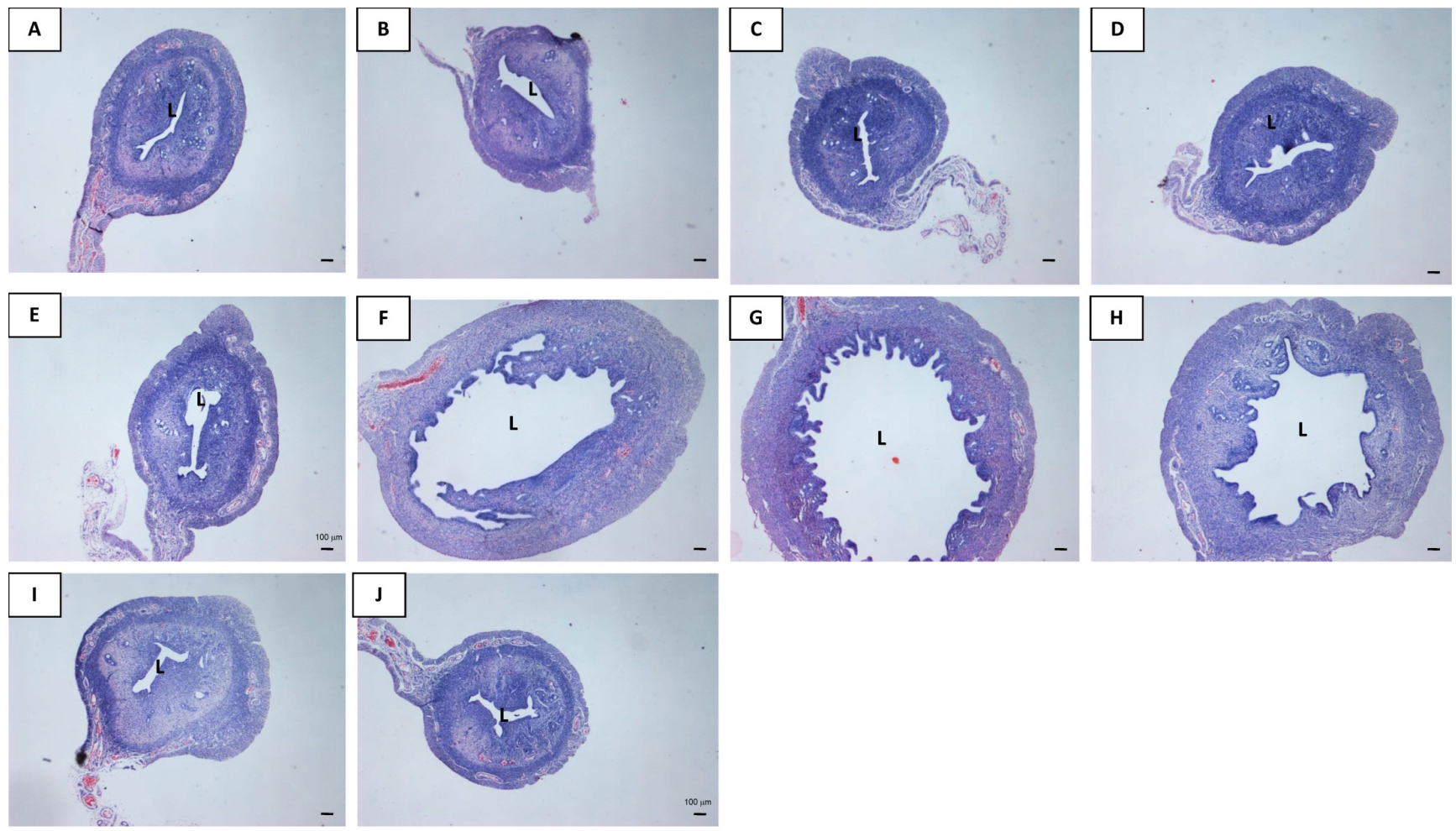

Figure 4: Representative images of the uterine sections from OVX SD rats treated with (A) peanut oil (control), (B) $0.5 G$ (0.5 $\mathrm{mg} / \mathrm{kg} /$ day), (C) $5 \mathrm{G}$ (5 mg/kg/day), (D) I0G (10 mg/kg/day), (E) $25 \mathrm{G} \mathrm{(25} \mathrm{mg/kg/day),} \mathrm{(F)} 50 \mathrm{G}$ (50 mg/kg/day, (G) I00G (I00 mg/kg/day), (H) E, (I) $\mathrm{P}$ and (J) DMSO for 3 consecutive days. There was an obvious increase in the size of the lumen following I00G treatment. Sections were stained with H\&E, Magnification X4. L indicates uterine lumen. (G-genistein, E-I $7 \beta$-oestradiol, P-progesterone), $n=6$ per treatment group.

In figure 5, the number and size of the uterine glands increased with increasing doses of genistein treatment. Treatment with $100 \mathrm{mg} / \mathrm{kg} /$ day genistein resulted in a significant increase in the number of glands as compared to E, control, DMSO and lower doses of genistein treatment $(<50 \mathrm{mg} / \mathrm{kg} /$ day $)$. The average size of the glandular lumen also increased with increasing doses of genistein treatment. Treatment with $50 \mathrm{mg} / \mathrm{kg} /$ day and $100 \mathrm{mg} / \mathrm{kg} /$ day genistein resulted in 2.30 and 2.64 times increase respectively in the glandular circumference as compared to control. $P$ treatment resulted in an increase in number but not the size of the glands, while treatment with lower genistein doses $(0.5,5$ and $10 \mathrm{mg} / \mathrm{kg} /$ day $)$ and DMSO did not cause any significant changes in the number and size of the glands as compared to control.

In figure 6 and table 3, the heights of the luminal epithelia increased following treatment with 25, 50 and $100 \mathrm{mg} / \mathrm{kg} /$ day genistein as compared to control $(\mathrm{p}<0 / 05)$. Treatment with 50 and $100 \mathrm{mg} / \mathrm{kg} /$ day genistein resulted in 1.69 and 2.12 times increase in heights respectively as compared to control. No significant changes in heights were noted following treatment with lower doses of genistein as compared to the control and DMSO treated groups. Meanwhile, treatment with $\mathrm{P}$ resulted in a significant increase in the luminal epithelial heights as compared to control $(p<0.05)$. In general, the height of the glandular epithelial was found to be lower than the height of the luminal epithelia. Following treatment with 50 $\mathrm{mg} / \mathrm{kg} /$ day genistein, glandular epithelial height increased 1.6 times while $100 \mathrm{mg} / \mathrm{kg} /$ day genistein treatment resulted in 2.16 times increase in height as compared to control. Treatment with $100 \mathrm{mg} / \mathrm{kg} /$ day genistein resulted in 1.24 times increase in heights as compared to E treated group. No significant changes in height were noted following treatment with lower genistein doses and DMSO as compared to control. 
Table 2: Analyses of the circumference (C) of the uterine glandular lumen and the average number of the glands in the uterine section following treatment with different doses of genistein: $0.5 \mathrm{G}$ ( $0.5 \mathrm{mg} / \mathrm{kg} / \mathrm{day}), 5 \mathrm{G}(5 \mathrm{mg} / \mathrm{kg} /$ day $), 10 \mathrm{G}(10 \mathrm{mg} / \mathrm{kg} / \mathrm{day}), 25 \mathrm{G}$ (25 $\mathrm{mg} / \mathrm{kg} / \mathrm{day})$, $50 \mathrm{G}(50 \mathrm{mg} / \mathrm{kg} / \mathrm{day})$ and $100 \mathrm{G}(100 \mathrm{mg} / \mathrm{kg} / \mathrm{day})$, I7 $\beta$-oestradiol $(E)$, progesterone $(\mathrm{P})$ and DMSO. Values represent mean \pm SEM with $n=6$ per group. The glandular luminal circumference increased with increasing doses of genistein treatment. Meanwhile, the average number of glands per cross section also increased with increasing doses of genistein treatment. $\dagger(p<0.05$ as compared to control), * ( $<<0.05$ as compared to $E$ ).

\begin{tabular}{lll}
\hline & $\begin{array}{c}\text { Glandular luminal cir- } \\
\text { cumference }(\mu \mathrm{m})\end{array}$ & $\begin{array}{c}\text { Number of glands/cross } \\
\text { section }\end{array}$ \\
\hline Control & $77.26 \pm 5.42^{*}$ & $10 \pm 3^{*}$ \\
gen 0.5 & $79.77 \pm 4.50^{*}$ & $16 \pm 4^{*}$ \\
gen 5.0 & $77.90 \pm 3.98^{*}$ & $17 \pm 3^{*}$ \\
gen 10 & $98.58 \pm 4.56^{*}$ & $15 \pm 3^{*}$ \\
gen 25 & $129.90 \pm 4.77^{\dagger}$ & $30 \pm 5 \dagger$ \\
gen 50 & $196.55 \pm 6.56^{\dagger}$ & $39 \pm 6 \dagger$ \\
gen 100 & $225.90 \pm 6.75^{\dagger},{ }^{*}$ & $51 \pm 8 \dagger^{*}{ }^{*}$ \\
E & $207.34 \pm 6.98^{\dagger}$ & $31 \pm 5 \dagger$ \\
P & $80.52 \pm 4.76^{*}$ & $25 \pm 3 \dagger^{*}{ }^{*}$ \\
DMSO & $77.05 \pm 5.90^{*}$ & $13 \pm 4^{*}$ \\
\hline
\end{tabular}

Table 3: Analyses of the heights of the uterine luminal and glandular epithelia following treatment with different doses of genistein : $0.5 \mathrm{G}(0.5 \mathrm{mg} / \mathrm{kg} /$ day $), 5 \mathrm{G}(5 \mathrm{mg} / \mathrm{kg} /$ day $), \quad 10 \mathrm{G}(10$ $\mathrm{mg} / \mathrm{kg} /$ day $)$, $25 \mathrm{G}(25 \mathrm{mg} / \mathrm{kg} /$ day $)$, $50 \mathrm{G}(50 \mathrm{mg} / \mathrm{kg} /$ day $)$ and I00G ( $100 \mathrm{mg} / \mathrm{kg} /$ day), I7 $\beta$-oestradiol (E), progesterone (P) and DMSO. Values represent mean \pm SEM with $n=6$ per group. $A$ dose-dependent increase in the epithelial heights was noted with increasing doses of genistein treatment. $\dagger(p<0.05$ as compared to control), * $(\mathrm{p}<0.05$ as compared to $\mathrm{E})$.

\begin{tabular}{lll}
\hline & $\begin{array}{l}\text { Luminal Epithelial } \\
\text { Height }(\mathrm{H})(\mu \mathrm{m})\end{array}$ & $\begin{array}{l}\text { Glandular Epithelial } \\
\text { Height }(\mu \mathrm{m})\end{array}$ \\
\hline Control & $13.88 \pm 0.75^{*}$ & $11.25 \pm 0.71^{*}$ \\
gen 0.5 & $11.67 \pm 0.85^{*}$ & $10.48 \pm 0.80^{*}$ \\
gen 5.0 & $11.06 \pm 0.93^{*}$ & $11.46 \pm 0.62^{*}$ \\
gen 10 & $12.04 \pm 0.63^{*}$ & $11.75 \pm 0.58^{*}$ \\
gen 25 & $17.07 \pm 0.37^{\dagger}{ }^{*}$ & $13.67 \pm 1.02^{*}$ \\
gen 50 & $24.83 \pm 1.49^{\dagger}$ & $18.16 \pm 1.01^{\dagger}$ \\
gen 100 & $30.51 \pm 0.88^{\dagger}$ & $24.34 \pm 1.03^{\dagger}{ }^{\dagger}{ }^{*}$ \\
E & $28.47 \pm 1.25^{\dagger}$ & $19.60 \pm 0.98^{\dagger}$ \\
P & $17.05 \pm 0.82^{*}$ & $12.43 \pm 0.75^{*}$ \\
DMSO & $14.10 \pm 0.66^{*}$ & $12.70 \pm 0.86^{*}$ \\
\hline
\end{tabular}
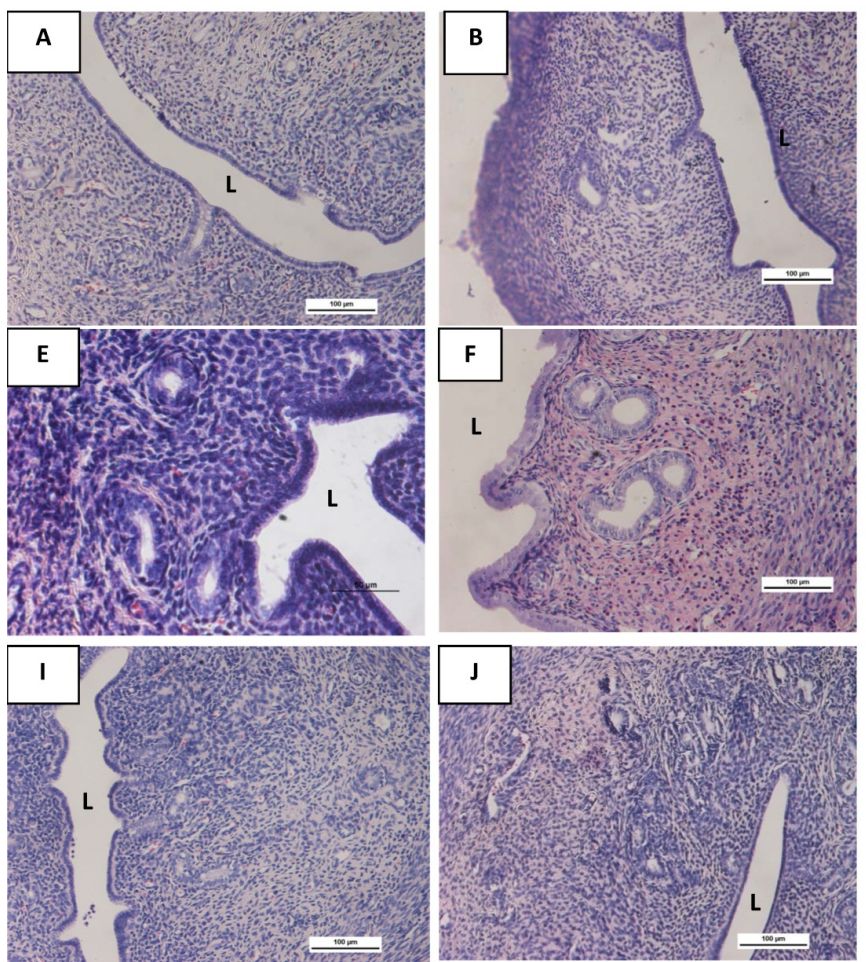
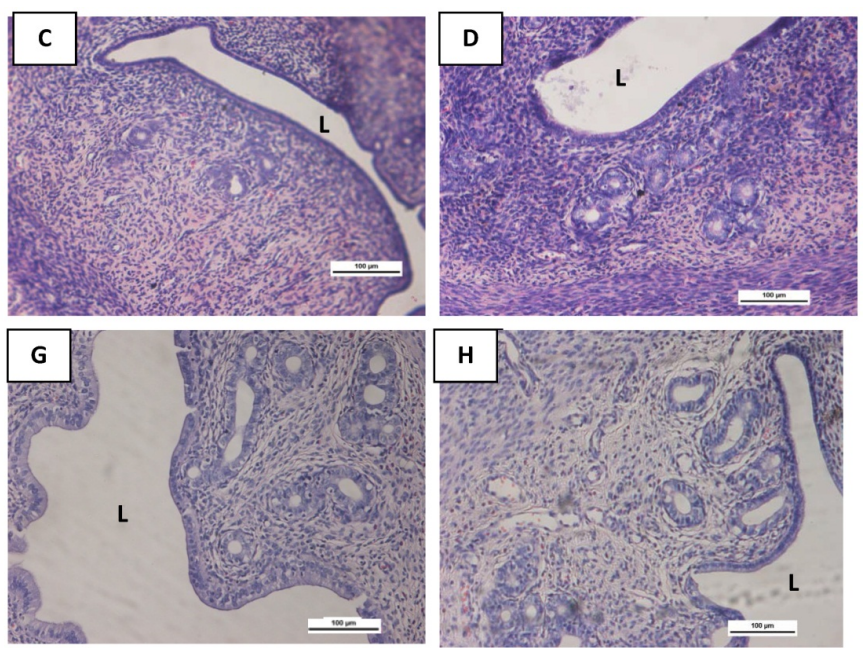

Figure 5: Representative images of the uterine sections from OVX SD rats treated with (A) peanut oil (control), (B) $0.5 G$ (0.5 $\mathrm{mg} / \mathrm{kg} / \mathrm{day}$ ), (C) $5 \mathrm{G}$ (5 mg/kg/day), (D) $10 \mathrm{G} \mathrm{(10} \mathrm{mg/kg/day),} \mathrm{(E)} 25 \mathrm{G}$ (25 mg/kg/day), (F) $50 \mathrm{G} \mathrm{(50} \mathrm{mg/kg/day,} \mathrm{(G)} 100 \mathrm{G}$ (I00 mg/kg/day), (H) E, (I) P and (J) DMSO for 3 consecutive days. There was a remarkable increase in the number of uterine glands following I00G treatment. Meanwhile, the size of the glands was noted to increase with increasing doses of genistein treatment. Sections were stained with H\&E, Magnification X20. L indicates uterine lumen. (G-genistein, E- I7 $\beta$-estradiol, P-progesterone), $n=6$ per treatment group. 

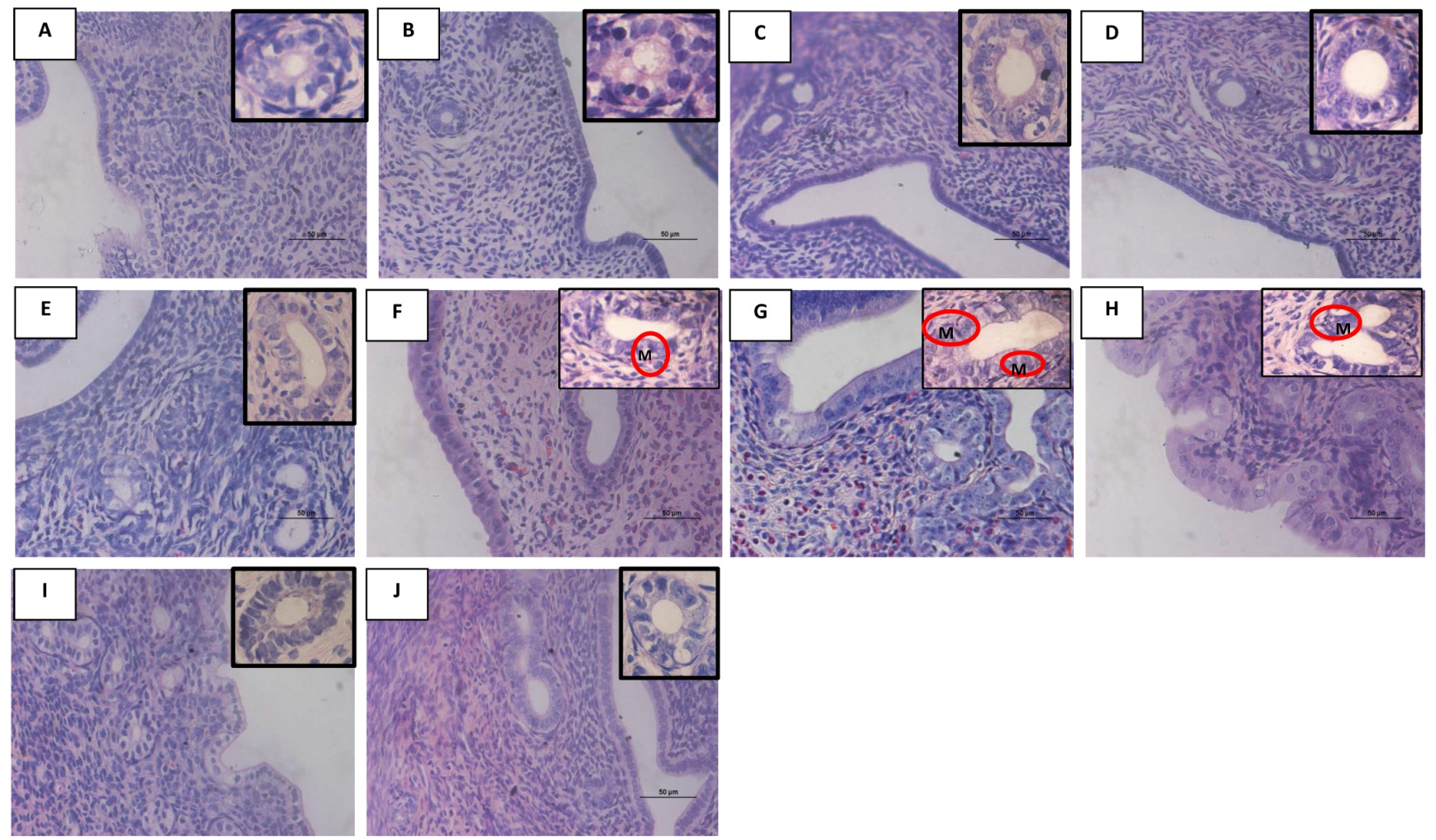

Figure 6: Representative images of the uterine glandular epithelia and luminal epithelia under high power field (X40 for the luminal epithelia and XI00 for the glandular epithelia-in the upper right hand corner) from OVX SD rats treated with (A) peanut oil (control), (B) 0.5G (0.5 mg/kg/day), (C) $5 \mathrm{G} \mathrm{(5} \mathrm{mg/kg/day),} \mathrm{(D)} \mathrm{IOG} \mathrm{(10} \mathrm{mg/kg/day),} \mathrm{(E)} 25 \mathrm{G} \mathrm{(25} \mathrm{mg/kg/day),} \mathrm{(F)} 50 \mathrm{G} \mathrm{(50} \mathrm{mg/kg/day,} \mathrm{(G)} \mathrm{I00G} \mathrm{(I00}$ $\mathrm{mg} / \mathrm{kg} /$ day ), (H) E, (I) P and (J) DMSO for 3 consecutive days. The luminal and glandular epithelial heights increased with increasing doses of genistein treatment. L indicates uterine lumen. G-genistein, E-I7 $\beta$-estradiol, P- progesterone. Sections were stained with H\&E. G -uterine gland; $M$ - mitosis, $n=6$ per treatment group.

\subsection{Uterine PCNA expression}

In figure 7 , there was a dose-dependent increase in the uterine PCNA expression with increasing doses of genistein treatment. The expression of uterine PCNA significantly increased following treatment with genistein at doses exceeding $10 \mathrm{mg} / \mathrm{kg} /$ day as compared to control. Treatment with 100 $\mathrm{mg} / \mathrm{kg} /$ day genistein resulted in the highest increased in PCNA expression (2.85 folds). This increase was significantly higher than following $\mathrm{E}$ treatment (2.30 folds). The molecular weight of PCNA was detected at $34 \mathrm{kDa}$.

Figure 7: The levels of expression of uterine PCNA and the representative image of the blot of total uterine homogenate from ovariectomized rats treated with $0.5 \mathrm{G}(0.5 \mathrm{mg} / \mathrm{kg} /$ day $), 5 \mathrm{G}$ $(5 \mathrm{mg} / \mathrm{kg} /$ day $)$, I0G( $10 \mathrm{mg} / \mathrm{kg} /$ day $)$, $25 \mathrm{G}(25 \mathrm{mg} / \mathrm{kg} /$ day $), 50 \mathrm{G}(50$ $\mathrm{mg} / \mathrm{kg} / \mathrm{day})$ and $100 \mathrm{G}(100 \mathrm{mg} / \mathrm{kg} /$ day $)$, I7 $\beta$-oestradiol $(\mathrm{E})$. Treatment with $100 \mathrm{G}$ resulted in a significant increase in PCNA protein expression as compared to $E$. The molecular weight of PCNA was detected at $34 \mathrm{kDa}$. G-genistein, $n=6$, Data was expressed as mean \pm SEM, $*(p<0.05)$ as compared to control, $\dagger$ ( $p<0.05$ as compared to $E)$.

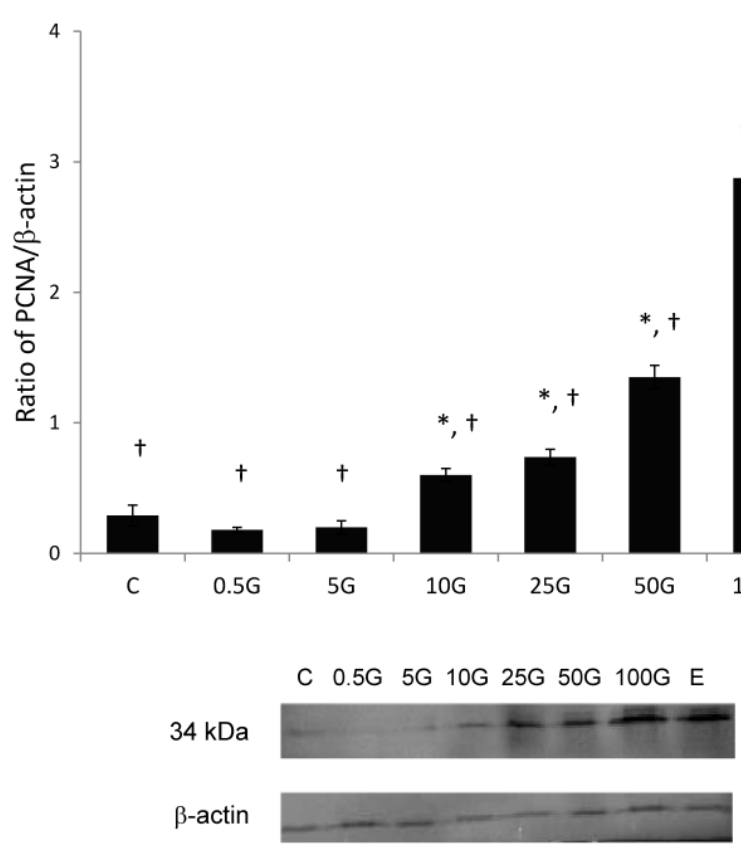




\subsection{Serum Genistein Level}

In figure 8 , there was a dose-dependent increase in serum genistein level following increasing doses of genistein treatment. Subcutaneous injection of 100 $\mathrm{mg} / \mathrm{kg} /$ day genistein resulted in plasma level of 15.6 $\mathrm{mM}$, which was 14 times higher than the level achieved following $5 \mathrm{mg} / \mathrm{kg} /$ day genistein injection $(1.1 \mathrm{mM})$. Meanwhile, subcutaneous injection of 50 $\mathrm{mg} / \mathrm{kg} /$ day genistein resulted in 65.8 times increase in plasma genistein level as compared with $0.5 \mathrm{mg} / \mathrm{kg} /$ day genistein.

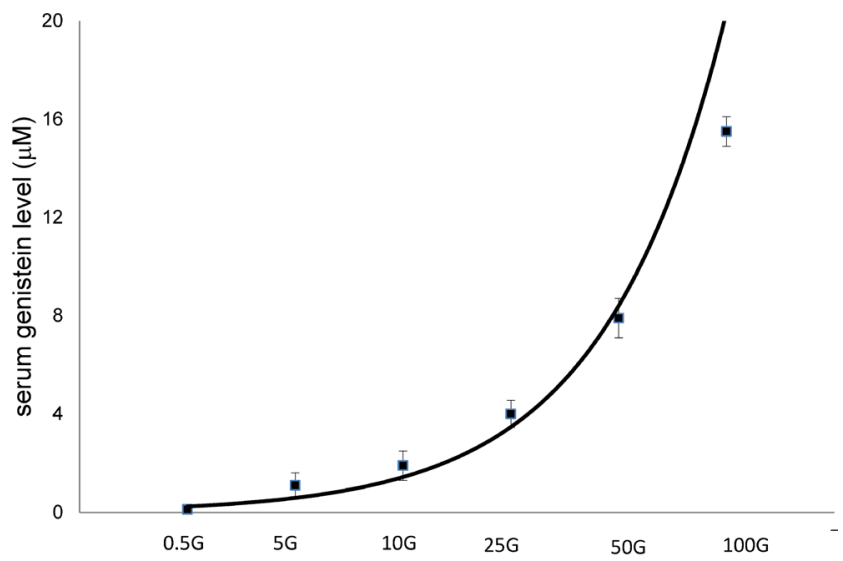

Figure 8: The serum level following subcutaneous treatment with different doses of genistein : $0.5 \mathrm{G}(0.5 \mathrm{mg} / \mathrm{kg} /$ day $), 5 G \quad(5$ $\mathrm{mg} / \mathrm{kg} /$ day), IOG (10 mg/kg/day), 25G (25 mg/kg/day), 50G (50 $\mathrm{mg} / \mathrm{kg} /$ day $)$ and I00G $(100 \mathrm{mg} / \mathrm{kg} /$ day $)$. Data were expressed as mean \pm SEM, $n=6$.

\section{Discussion}

Despite of the reported adverse uterine effects related to high genistein intake in the neonates [13], the effect of genistein on the uterus of adult who presumably have never been exposed or minimally exposed to this compound during their pre-pubertal life period has not been fully elucidated. So far, there were only few studies which report on the effect of genistein on the uterus following adult exposure to this compound. These include an increase in the uterine weight and thickness [20] and proliferation of the uterine epithelial cells $[20,23]$. In this study, we have also demonstrated that treatment with genistein has resulted in a dose-dependent increase in uterine/body weight. In view that the effect of genistein on the uterus of adult has not been fully discovered, we therefore aim to investigate some of these effects which could explain the increased incidence of infertility related to high intake of this compound.

To the best of our knowledge, this study is the first to reveal that genistein stimulates fluid secretion in the uterus of female adult. Our findings indicate that treatment with genistein at 25, 50 and 100 $\mathrm{mg} / \mathrm{kg} /$ day resulted in a remarkable increase in the rate of uterine fluid secretion as compared to control. Meanwhile, the rate of fluid secretion following treatment with $100 \mathrm{mg} / \mathrm{kg} /$ day genistein far exceeded that following E treatment, which was known to induce fluid secretion in the uterus [21]. Treatment with $\mathrm{P}$ however resulted in a decrease in the rate of uterine fluid secretion as compared to control. Any changes in the fluid secretion rate will result in parallel changes in the uterine fluid volume. Changes in the fluid volume were reflected by changes in the concentration of F-dextran, a non-absorbable, high molecular weight fluorescence marker. F-dextran has been used to investigate fluid volume changes in various organs including colon [24] and uterus [21]. Following genistein treatment, a dose-dependent decrease in F-dextran concentration indicates increasing amount of fluid in the uterine lumen. Meanwhile, E treatment also resulted in a decrease in F-dextran concentration. Treatment with $\mathrm{P}$ however resulted in vice versa which indicates a reduction in fluid volume, most likely due to P-induced fluid absorption in the uterus [22]. The observed effects of genistein on the rate of uterine fluid secretion as well as on the volume of this fluid suggest that it could potentially affect fertility via inducing changes in the normal volume of the uterine fluid, thus this could explain the reported increase in the incidence of infertility related to high intake of this compound [5].

The findings from functional studies were supported by morphological evidences which indicate an increase in the circumferences of the uterine and uterine glandular lumens following treatment with increasing doses of genistein. An increase in the luminal circumference suggests an increase in the amount of fluid in the uterine lumen. A marked increase in the uterine luminal and glandular circumferences as noted following treatment with 100 $\mathrm{mg} / \mathrm{kg} /$ day genistein, indicates that excessive fluid accumulates in the uterus under this condition. Other evidence of genistein-induced fluid accumulation include the observed decrease in the endometrial thickness following treatment with high doses of genistein $(25,50$ and $100 \mathrm{mg} / \mathrm{kg} /$ day) which suggest that excessive fluid in the lumen could result in compression of the endometrial compartment. Thickness of the myometrium however was not affected by the increase in the amount of fluid in the uterine lumen. Meanwhile, myometrial thickness was found to increase with increasing doses of genistein, suggesting that genistein stimulates myometrial hypertrophy, consistent with the findings by Moller et al, [25]. Excessive fluid in the uterus may cause adverse effects on multiple reproductive processes which include 
interference with normal sperm transport, fertilization, embryo transport and implantation. Excessive fluid accumulation could also inhibit the uterine closure mechanism, which is thought necessary to initiate a close contact between the embryo and endometrial wall prior to implantation, especially in species such as rodents and humans [26]. As a result of failure of the uterus to 'close', implantation will not occur, resulting in infertility. Other cases of infertility-related excessive fluid accumulation in the female reproductive tract have been reported in hydrosalphinx, a pathological condition related to an excess fluid in the tubal lumen [27].

In this study, treatment with high genistein doses (50 and $100 \mathrm{mg} / \mathrm{kg} /$ day) were also found to induce remarkable changes to the uterine morphology in which it caused an increase in the number of glands as well as mitotic figures. These findings indicate that high genistein doses stimulate hyperplastic changes in the uterus. Evidences of uterine hyperplasia has been reported following acute, high dose (53 $\mathrm{mg} / \mathrm{kg} /$ day) [23] and chronic, low dose (1.6 $\mathrm{mg} / \mathrm{kg} /$ day) genistein treatments [28]. Our findings also indicate that treatment with high genistein doses resulted in a significant increase in the expression of PCNA, a marker for cellular proliferation [29]. This confirmed the hyperplastic changes which have been shown in the uterus from the morphological observations. Hyperplasia could lead to cancer development. Recently, genistein has been shown to promote the development of endometrial cancer in rats where administration of $150 \mathrm{mg} / \mathrm{kg} /$ day of this compound orally stimulates excessive epithelial proliferation [30]. Similar study by Kakehashi et al, [30] also reported that chronic genistein treatment has resulted in an increase in the incidence of atypical hyperplasia in the endometrium with a tendency for adenocarcinoma development. Meanwhile, chronic consumption of $150 \mathrm{mg} /$ day genistein in human for 5 years has been found to induce the development of endometrial hyperplasia [31], although its progression to cancer is so far unknown.

In other tissues for examples the mammary glands and vagina, high doses of genistein treatment has also been found to increase the risk for cancer development. Administration of genistein at 53 $\mathrm{mg} / \mathrm{kg} /$ body weight in rats were found to induce proliferation of the mammary glands epithelia [23], while treatment with $150 \mathrm{mg} / \mathrm{kg} /$ day genistein has been reported to increase the incidence of mammary adenocarcinoma [30]. High genistein intake has been reported to induce hyperplastic changes in the vagina of neonates [32] and adult [23]. Apart from the tendency for malignant transformation, epithelial hyperplasia could also affect normal endometrial de- velopment, thus this could interfere with the process of implantation [33]. Changes in endometrial morphology as reported in Polycystic Ovarian Disease (PCO), which was featured by a prolonged proliferative phase [34] have been proposed to affect fertility. We speculate that hyperplastic changes in the endometrium may inhibit its transformation into a receptive state, therefore may interfere with implantation. Apart from genistein, other environmental oestrogens for examples bisphenol-A (BPA) and p-tert-octylphenol (OCT) have been found to induce changes in the uterine morphology [2], which could also affect normal fertility.

Our findings have shown that the height of the uterine epithelia increased with increasing doses of genistein treatment. Following treatment with 100 $\mathrm{mg} / \mathrm{kg} /$ day genistein, the height was twice of that following low doses genistein treatment $(<10$ $\mathrm{mg} / \mathrm{kg} /$ day). Previous studies have reported genistein-induced increase in the epithelial heights. Diel et al, $[17,20]$ reported that orally administered genistein for 3 days at 50 and $100 \mathrm{mg} / \mathrm{kg} /$ day have resulted in an increase in the thickness of the uterine and vaginal epithelia. Schmidt et al, [2] meanwhile reported that 3 days oral genistein administration at $100 \mathrm{mg} / \mathrm{kg} /$ day did not cause any significant changes in the uterine epithelial thickness, although it resulted in an increase in the thickness of the vaginal epithelia. Meanwhile, Diel et al, [19] reported that subcutaneous genistein at $10 \mathrm{mg} / \mathrm{kg} /$ day did not affect the epithelial height although it was found to decrease the uterine PCNA expression. Chronic, low dose genistein treatment via subcutaneous injection at $1.6 \mathrm{mg} / \mathrm{kg} /$ day have also been found to induce hypertrophy and hyperplasia of the uterine luminal and glandular epithelia in rats[28]. The inconsistency in these findings could be due to differences in routes and duration of genistein treatment. Oral administration has been shown to produce lower effects as compared to subcutaneous treatment, in which the latter was found to result in higher plasma bioavailability [9] and greater tissue response [8]. Our findings have also shown that treatment with $\mathrm{E}$ and $\mathrm{P}$ resulted in a significant increase in the epithelial heights as compared to control, which indicate that these steroids are required for normal endometrial functions, as have been previously documented.

What would be the mean plasma genistein concentration that produced these adverse uterine effects? From our study, the mean plasma level achieved following subcutaneous injection of 50 and $100 \mathrm{mg} / \mathrm{kg} /$ day genistein were 7.9 and $15.5 \mu \mathrm{M}$ respectively. These levels were rarely achieved following normal dietary exposure to soy isoflavone even in the population who traditionally consumed high 
amount of soy-based products, in which the mean reported level was $0.5 \mu \mathrm{M}$ [35]. The highest plasma genistein level was reported among the Japanese women at $0.744 \mu \mathrm{M}$ [7]. Plasma genistein concentration could reach up to $10 \mu \mathrm{M}$, as has been documented in infant fed exclusively on soy-based formula [36]. Based on this observation, there is a possibility that plasma genistein concentration in adult could reach this level, mainly following consumption of genistein-rich dietary supplements.

In conclusion, this study has provided evidences on the effect of high dose genistein treatment on the fluid volume and morphology of the uterus in adult. Using rat model, we have shown that genistein stimulates uterine fluid secretion and excessive fluid accumulation in the uterine lumen. Additionally, we have also shown that high doses of genistein could induce hyperplastic and hypertrophic changes in the uterus. These effects show significance towards normal fertility where disturbances in the normal volume of the uterine fluid and morphology of the uterus could potentially cause infertility. In addition, morphological changes that occur in the uterus could also increase the risk of malignancy.

\section{Acknowledgements}

This study is funded by UMRG grant, University of Malaya, Kuala Lumpur, Malaysia.

\section{Conflict of interest}

The authors have nothing to disclose.

\section{References}

1. Kuhnle G, et al. Variability of phytoestrogen content in foods from different sources. Food Chemistry. 2009; 113(4): 1184-1187.

2. Schmidt S, et al. Hormonal activity of combinations of genistein, bisphenol A and 17beta-estradiol in the female Wistar rat. Arch Toxicol. 2006; 80(12): 839-45.

3. Floyd KA, et al. Genistein and genistein-containing dietary supplements accelerate the early stages of cataractogenesis in the male ICR/f rat. Experimental Eye Research. 2011; 92(2): 120-127.

4. Song $\mathrm{F}$, et al. Biodegradable soy protein isolate-based materials: a review. Biomacromolecules. 2011; 12(10): 3369-80.

5. Bennetts $\mathrm{H}$, et al. The oestrogenic effects of subterranean clover ( $\mathrm{T}$. subterraneum). Aust J Exp Biol Med Sci, 1951. 29: 249-253.

6. Setchell K, Gosselin SJ, Welsh MB, Johnston JO, Balistreri WF, Kramer LW, Dresser BL, Tarr MJ. Dietary estrogens--a probable cause of infertility and liver disease in captive cheetahs. Gastroenterology. 1987; 93: 225-33.

7. Adlercreutz H, Yamada T, Wahala K, \& Watanabe S. Maternal and neonatal phytoestrogens in Japanese women during birth. Am J Obst Gynecol. 1999; 180: 737-43.

8. Jefferson W, Padilla-Banks E, Newbold RR. Disruption of the female reproductive system by the phytoestrogen genistein. Reprod Toxicol., 2007; 23(3): 308-16

9. Jefferson W, Williams CJ. Circulating levels of genistein in the neonate, apart from dose and route, predict future adverse female reproductive outcomes. Reprod Toxicol. 2011; 31(3): 272-9.

10. Jefferson $\mathrm{W}$, et al. Neonatal exposure to genistein induces estrogen receptor (ER)alpha expression and multioocyte follicles in the maturing mouse ovary: evidence for ERbeta-mediated and nonestrogenic actions. Biol Reprod. 2002; 67: 1285- 1296.
11. Jefferson $\mathrm{W}$, et al. Oral exposure to genistin, the glycosylated form of genistein, during neonatal life adversely affects the female reproductive system. Environ Health Perspect. 2009; 117(12): 1883-9.

12. Jefferson $\mathrm{W}$, et al. Neonatal genistein treatment alters ovarian differentiation in the mouse: inhibition of oocyte nest breakdown and increased oocyte survival. Biol Reprod. 2006; 74: 161-168.

13. Jefferson $W$, et al. Neonatal exposure to genistein disrupts ability of female mouse reproductive tract to support preimplantation embryo development and implantation. Biol Reprod. 2009; 80(3): 425-31.

14. Jefferson $\mathrm{W}$, et al. Adverse effects on female development and reproduction in CD-1 mice following neonatal exposure to the phytoestrogen genistein at environmentally relevant doses. Biol Reprod. 2005; 73: 798-806

15. Padilla-Banks E, Jefferson WN. Newbold RR, Neonatal exposure to the phytoestrogen genistein alters mammary gland growth and developmental programming of hormone receptor levels. Endocrinology. 2006; 147: 4871-4882.

16. Nagao T, et al. Reproductive effects in male and female rats of neonatal exposure to genistein. Reproductive Toxicology. 2001; 15(4): 399-411.

17. Diel $\mathrm{P}$, et al. Phytoestrogens and carcinogenesis-differential effects of genistein in experimental models of normal and malignant rat endometrium. Human Reproduction. 2001; 16(5): 997-1006.

18. Giudice LC. Endometrium in PCOS: Implantation and predisposition to endocrine CA. Best Practise \& Research Clinical Endocrinology \& Metabolism. 2006; 20: 235-244.

19. Diel $\mathrm{P}$, et al. Combinatorial effects of the phytoestrogen genistein and of estradiol in uterus and liver of female Wistar rats. The Journal of Steroid Biochemistry and Molecular Biology. 2006; 102: 60-70.

20. Diel $P$, et al. The differential ability of the phytoestrogen genistein and of estradiol to induce uterine weight and proliferation in the rat is associated with a substance specific modulation of uterine gene expression. Molecular and Cellular Endocrinology. 2004; 221: 21-32.

21. Salleh N. et al. The hormonal control of uterine luminal fluid secretion and absorption. J Membr Biol. 2005; 206(1): 17-28.

22. Naftalin R, Thiagarajah JR, Pedley KC, Pocock VJ, Milligan SR. Progesterone stimulation of fluid absorption by the rat uterine gland. Reproduction. 2002; 123(5): 633-8.

23. Rimoldi $G$, et al. Effects of chronic genistein treatment in mammary gland, uterus, and vagina. Environ Health Perspect. 2007; 115: 62-8.

24. Thiagarajah JR, Pedley KC, \& Naftalin RJ. Evidence of amiloride-sensitive fluid absorption in rat descending colonic crypts from fluorescence recovery of FITC-labelled dextran after photobleaching. J Physiol.. 2001;536: 541-553.

25. Möller F, et al. The rat prepubertal uterine myometrium and not the luminal epithelium is predominantly affected by a chronic dietary genistein exposure. Archives of Toxicology. 2012; 86(12): 1899-1910.

26. Lopata A, B-L U. Enders A "Pinopodes" and Implantation. Reviews in Endocrine and Metabolic Disorders. 2002; 3(2): 77-86.

27. Strandell A, and Lindhard A. Why does hydrosalpinx reduce fertility?: The importance of hydrosalpinx fluid. Human Reproduction. 2002; 17(5): 1141-1145.

28. Retana-Márquez S, et al. Mesquite pod extract modifies the reproductive physiology and behavior of the female rat. Hormones and Behavior. 2012; 61(4): 549-558.

29. Schimmelpenning $\mathrm{H}$, et al. Prognostic value of the combined assessment of proliferating cell nuclear antigen immunostaining and nuclear DNA content in invasive human mammary carcinomas. Virchows Arch A Pathol Anat Histopathol. 1993, 1993; 423(4): 273-9.

30. Kakehashi A, et al. Hormonally Active Doses of Isoflavone Aglycones Promote Mammary and Endometrial Carcinogenesis and Alter the Molecular Tumor Environment in Donryu Rats. Toxicological Sciences. 2012; 126(1): 39-51.

31. Unfer V, et al. Endometrial effects of long-term treatment with phytoestrogens: a randomized, double-blind, placebo-controlled study. Fertility and Sterility, 2004; 82(1): 145-148.

32. Bernbaum JC, et al. Pilot studies of estrogen-related physical findings in infants. Environ Health Perspect. 2008; 116(3): 416-20.

33. Nikas G, and Makrigiannakis A. Endometrial Pinopodes and Uterine Receptivity. Annals of the New York Academy of Sciences., 2003; 997(1): 120-123.

34. Rudnicka E, Wierzba W, and Radowicki S. Evaluation of endometrial histologic morphology in patients with polycystic ovary syndrome. Ginekol Pol. 2009; 80(2): 103-6.

35. Morton MS, et al. Phytoestrogen Concentrations in Serum from Japanese Men and Women over Forty Years of Age. The Journal of Nutrition. 2002;132(10): 3168-3171.

36. Cao $Y$, et al. Isoflavones in urine, saliva, and blood of infants: data from a pilot study on the estrogenic activity of soy formula. J Expos Sci Environ Epidemiol. 2008; 19(2): 223-234 